\title{
OS DIFERENTES PROCEDIMENTOS DE AQUISIÇÃO DE BENS POR DISPENSA DE LICITAÇÃO NA EMBRAPA/CNPMF
}

\author{
THE DIFFERENT PROCEDURES FOR NO-BID ACQUISITION IN EMBRAPA/CNPMF
}

\author{
George Araújo dos Reis* \\ Aline Barbosa de Oliveira** \\ Igor Dantas Fraga***
}

\begin{abstract}
A licitação é o meio utilizado por entidades públicas para que sejam efetuadas as aquisições e contratações; porém, há casos específicos em que é dispensável a sua realização. Nessas ocasiões, aplica-se a sua inexigibilidade ou a sua dispensa. A dispensa de licitação, objeto da presente pesquisa, pode ser realizada por dois procedimentos diferentes: o primeiro é o método tradicional, que fora adotado desde a implementação da Lei 8.666/1993 e, o segundo, é a cotação eletrônica, que foi regulamentada através da Portaria n 306/2001 como uma forma de buscar maior transparência, redução de custos e agilidade nos processos de aquisição. Neste contexto, o trabalho objetivou avaliar comparativamente, em relação à tempestividade, economicidade e competitividade, como ocorre o processo de aquisição de bens em situações de dispensa de licitação na Empresa Brasileira de Pesquisa Agropecuária (EMBRAPA/CNPMF), situada na cidade de Cruz das Almas BA. Para alcançar esse objetivo, realizou-se uma pesquisa descritiva, de caráter quali-quantitativo, através de um estudo de caso. Os dados analizados provem do levantamento e análise dos processos de dispensa tradicional e por cotação eletrônica, realizados na EMBRAPA durante os anos de 2009 a 2016. Os dados foram coletados de processos constantes no sitio de compras governamentais e de processos físicos arquivados na unidade. Os resultados encontrados demonstraram que a cotação eletrônica, no período de estudo, se mostrou mais vantajosa para a EMBRAPA do que a dispensa tradicional, visto que obteve uma maior tempestividade, prazos menores de realização e números maiores de fornecedores participantes, demonstrando elevada competitividade; e também obteve mais economicidade, pois a média de valores dos anos foi menor que o método tradicional.
\end{abstract}

Palavras-chave: Dispensa de Licitação. EMBRAPA. Cotação Eletrônica.

Bidding is the means used by public entities to make acquisitions and contracting, but there are specific cases in which the bidding is unnecessary. In those occasions, mechanisms such as the unenforceability or the waiver of bidding are used. The bidding waiver, subject of the present study, can be carried out by two different procedures: the traditional method that has been adopted since the implementation of Law 8.666/19933 or through electronic quotation, which was regulated by the Ministerial Directive no. 306/2001 as a way to achieve higher transparency, cost reduction and agility in acquisition processes. In this context, the objective of this work was to evaluate comparatively the timeliness, economicity and competitiveness of the governmental purchase process in situations of exemption from bidding at the Brazilian Agricultural Research Corporation (EMBRAPA/CNPMF), located in the city of Cruz das Almas - BA. In order to achieve this objective, a quantitative and qualitative descriptive research was carried out through a case study. The analyzed data were collected from the governmental purchases site and also from physical processes filed in the unit, and comprised the period of 2009 to 2016. The results showed that the electronic quotation in the studied period was more advantageous for EMBRAPA than the traditional dispensation, since it obtained greater timeliness, shorter periods of execution, and higher number of participating suppliers, showing high competitiveness; and also obtained more economicity, since the average values over the years were lower than the traditional method.

Keywords: Bidding Non-bid Aquisition. EMBRAPA. Electronic Quotation.

*Pós-Graduando em Licitações, Contratos e Convênios Administrativos - FAMAM; Graduado em Bacharelado em Ciências Contábeis FAMAM; Cruz das Almas - BA; Lattes: http://lattes.cnpq.br/0250622321027066; E-mail: george-f-10@hotmail.com

**Mestranda em Gestão de Politicas Públicas e Segurança Social - UFRB; Especialista em Auditoria e Pericia Contábil -FTC; Feira de Santana BA; Lattes: http://lattes.cnpq.br/6170878135187473;

E-mail: aline_barbosap@hotmail.com;

***Doutorando em Estado e Sociedade - UFSB; Mestre em Gestão de Políticas Públicas - UFRB; Feira de Santana - BA; Lattes: http://lattes.cnpq.br/2039458387584938 E-mail: igordantasfraga@gmail.com 


\section{INTRODUÇÃO}

A Administração Pública está obrigada a seguir a legislação, principalmente para realizar as aquisições e para as contratações, o que impõe a utilização da licitação, que pode adotar diversas modalidades, apresentadas através das Leis $n^{\circ} 8.666 / 1993$, a $n^{\circ} 10.520 / 2002$ e a $n^{\circ} 12.462 / 2011$. As duas últimas foram implementadas devido à necessidade de maior transparência, eficácia e redução de custos operacionais, instituindo as modalidades pregão e RDC (Regime Diferenciado de Contratação), respectivamente.

Já a Lei n 8.666/1993 estabelece as seguintes modalidades: concorrência, tomada de preços, convite, concurso e leilão (BRASIL, 1993). Porém, em alguns casos específicos, a realização da licitação torna-se inconveniente ao poder público. Diante disso, há situações na legislação que, quando ocorrem, utilizam a dispensa de licitação ou inexigibilidade, essa última em casos peculiares, de produtor exclusivo, natureza singular ou contratação de profissionais do setor artístico.

A dispensa de licitação se tornou uma alternativa, pois a compra ou contratação pode ser realizada com menos burocracia e intervalo de tempo, atendendo rapidamente à necessidade do órgão que a realizará em ocasiões emergenciais e aquisições de pequeno valor, já que foram decretados limites para compras de materiais e contratações para prestação de serviços, podendo ser realizada pelo método tradicional ou por cotação eletrônica.

Dessa forma, o presente estudo pretende responder ao seguinte questionamento: como a aquisição de bens que se enquadram nas situações de dispensa de licitação são realizadas em relação comparativa à tempestividade, economicidade e competitividade na EMBRAPA/CNPMF? O objetivo geral dessa pesquisa é avaliar comparativamente em relação à tempestividade, economicidade e competitividade, como ocorre o processo de aquisição de bens em situações de dispensa de licitação na EMBRAPA/CNPMF.

Em relação à justificativa deste estudo, observa-se a ausência de estudos com este viés e tendo a EMBRAPA como lócus, servindo também como uma forma de transparência para que a população identifique se os procedimentos utilizados pelos órgãos públicos são os mais adequados e se seus resultados revertem em maior ou menor economicidade e celeridade.

\section{REVISÃO DE LITERATURA}

\section{ADMINISTRAÇÃO PÚBLICA}

A Administração Pública é formada por órgãos do governo que estão designados à prestação de serviços à sociedade através de políticas públicas, constituindo-se dos Poderes Executivo, Legislativo e Judiciário nos âmbitos federal, estadual ou municipal, organizando uma hierarquia e possibilitando um controle das ações a serem exercidas pelos membros de cada poder. Esta informação é confirmada por Costin (2010, p. 27) que afirma que a Administração Pública:

Inclui o conjunto de órgãos, funcionários e procedimentos utilizados pelos três poderes que integram o Estado, para realizar suas funções econômicas e os papéis que a sociedade lhe atribuiu no momento histórico em consideração.

Em termos de classificações, a Administração Pública se caracteriza por duas formas: a direta (centralizada), composta por entes da federação: União, estados e municípios como os ministérios, secretarias e a Presidência da República ou a indireta (descentralizada), composta por autarquias, empresas públicas, fundações de direito público, sociedades de economia mista e serviços sociais autônomos.

Para Kohama (2010, p. 14), a "administração direta ou centralizada é aquela que se encontra integrada e ligada, na estrutura organizacional, diretamente ao chefe do Poder Executivo." E conclui sua definição comentando sobre a hierarquia a respeito da prestação de serviços, que é responsabilizada por 
diversas unidades; porém, devido ao fato de possuir um órgão superior, há um afunilamento notório que culmina no chefe máximo do Poder Executivo.

$\mathrm{Na}$ administração indireta os órgãos são responsáveis pela realização de atividades a que são destinados, ou seja, ocorre uma descentralização, que é definida por Silva (2014, p. 5) da seguinte forma: "Na descentralização, a entidade pública transfere serviços para outra entidade autônoma (caso do Poder Executivo quando transfere serviços para suas Autarquias)".

Portanto, conclui-se que há uma subordinação da administração indireta, visto que esta é responsável por realizar as atividades que lhe são designadas pela administração direta. Essa, por sua vez, encontra-se no centro da Administração Pública, pois além de desempenhar o que já é legalmente imposto, fica responsável por supervisionar a administração indireta, que goza de autonomia, porém, é subordinada a controle finalístico sobre efetivo cumprimento de seus objetivos.

\section{COMPRAS PÚBLICAS}

As compras públicas são realizadas com o intuito de suprir a necessidade de insumos para que os órgãos públicos possam desenvolver as atividades e realizem a prestação de serviços designados à população conforme determinado pelas políticas públicas.

Partindo do pressuposto que os atos dos órgãos da Administração Pública são embasados pelo princípio da legalidade, a Lei ${ }^{\circ} 8.666 / 1993$ em seu artigo $6^{\circ}$, Inciso III traz a definição de compras, como sendo "toda aquisição remunerada de bens para fornecimento de uma só vez ou parceladamente" (BRASIL, 1993). Tal definição pode ser utilizada para compras públicas e no setor privado, porém há diferenças entre as mesmas, como explica Dallari (1993, p. 29):

Enquanto os particulares podem fazer tudo aquilo que a lei não proíbe, a Administração só pode fazer aquilo que a lei determina. Os interesses privados são disponíveis, mas os interesses públicos são indisponíveis. Os particulares escolhem livremente seus contratantes, mas a Administração não tem liberdade de escolha.

Sendo assim, é notório que essas diferenças devem-se ao fato das empresas particulares estarem ligadas a um interesse privado do seu administrador/proprietário, e os procedimentos realizados seguem normas internas e exclusivas da entidade, enquanto que no setor público as normas são implementadas pelo Poder Legislativo através das leis.

Silva (2008, p. 61) lista as principais características que norteiam a aquisição: "os tipos de produtos adquiridos; a capacidade e estrutura da instituição compradora; os valores monetários envolvidos e o perfil dos fornecedores." E complementa que para se analisar o poder de compra do Estado, é importante o destaque para a licitação, devido ao procedimento se caracterizar como sendo o caminho que consolida as compras que são realizadas (SILVA, 2008).

A licitação é regulamentada pela Lei n $8.666 / 1993$, que em seu artigo $3^{\circ}$ indica que esta deve ser realizada seguindo:

\footnotetext{
A observância do princípio constitucional da isonomia, a seleção da proposta mais vantajosa para a administração e a promoção do desenvolvimento nacional sustentável e será processada e julgada em estrita conformidade com os princípios básicos da legalidade, da impessoalidade, da moralidade, da igualdade, da publicidade, da probidade administrativa, da vinculação ao instrumento convocatório, do julgamento objetivo e dos que lhes são correlatos (BRASIL, 1993).
}

Silva (2014) complementa que a licitação nada mais é que um meio de competição onde a Administração Pública deve escolher a proposta que melhor se adeque ao seu orçamento e com intuito da efetivação de um contrato para que se possam adquirir produtos e/ou serviços. Em concordância com Silva (2014) sobre a definição de licitação, Fernandes (2005, p. 197) especifica que a "A licitação abrange as compras de bens e a contratação de serviços, quando envolve o recebimento e a classificação entre 
propostas competitivas".

Portanto, nota-se que, ao realizar as licitações, há uma necessidade de serem selecionadas as propostas que resultem na melhor escolha em termos de custo-benefício para o órgão licitante ou seja, a economicidade. Além disso, a compra também deve atender à tempestividade, que nada mais é que atender a necessidade no momento correto; a compra deve ser realizada para suprir aquela demanda do momento, sendo assim será considerada tempestiva. É preciso também que haja competitividade entre os fornecedores, pois havendo competição entre os mesmos a tendência é de que os valores das compras caiam.

\section{MODALIDADES DE LICITAÇÃO}

A licitação é o procedimento utilizado por órgãos públicos para a realização das compras públicas, visando à transparência e vantagens, sobretudo econômicas, para a utilização adequada dos recursos e prestação dos serviços à população.

A realização da licitação tem seus pilares sustentados por leis, que definem critérios que direcionam os órgãos públicos quanto à burocracia da realização das compras públicas. Dentre essas leis, têm-se a Lei $n^{\circ} 8.666$ de 21 de junho de 1993 que institui normas gerais a serem seguidas para licitações. O artigo 22 define as seguintes modalidades: "I - concorrência; II - tomada de preços; III convite; IV - concurso; V - leilão." (BRASIL, 1993). Tais modalidades possuem critérios que as diferenciam entre si e são determinantes para suas devidas utilizações, como por exemplo, o tipo de licitação, o objeto a ser licitado e o valor estimado da contratação.

Dessa forma, quanto aos tipos de licitação, a Lei n 8.666/1993 enumera em seu Artigo 45 as seguintes possibilidades: "Menor preço, melhor técnica, técnica e preço e maior lance ou oferta." (BRASIL, 1993). É importante diferenciar modalidades de tipos de licitação que, por sua vez, envolvem os critérios de seleção da proposta.

A escolha do tipo de licitação é tão importante quanto a escolha da modalidade, pois é através da mesma que será definido o método de julgamento da proposta que se enquadre como a mais vantajosa para o órgão licitante, devendo ser definida antes da realização do procedimento licitatório e publicado no edital, que é o documento que determina as condições para participação dos licitantes, relata como será feita a licitação e a maneira como será efetuada a aquisição.

No decorrer do tempo houve a necessidade de melhoria dos procedimentos licitatórios, levando em conta tanto a demanda por maior economicidade quanto transparência nas compras públicas. Por esse motivo foi sancionada a Lei $\mathrm{n}^{\circ} 10.520$ em 17 de julho de 2002, que adota mais uma modalidade de licitação, o pregão, a ser utilizado para aquisições ou contratações que podem ser especificados de forma objetiva, também chamados de bens comuns (BRASIL, 2002).

O pregão pode ser realizado no procedimento presencial, que como explica Vasconcelos (2013, p. 3), "é realizada sessão presencial com a participação dos interessados que após a entrega, pelos licitantes, dos envelopes contendo a indicação do objeto e preços ofertados e respectiva habilitação inicia-se a fase de lances". O outro procedimento é o eletrônico, que acontece através de um sitio específico e funciona como um chat, onde há um pregoeiro responsável por comandar todas as etapas; por outro lado, estão os fornecedores que devem inserir suas propostas e as documentações solicitadas.

Além de todas as modalidades já mencionadas, houve também a efetivação do Regime Diferenciado de Contratação - RDC através da Lei 12.462/2011, instituída com a intenção voltada para a realização de licitações que envolvem obras de programas do governo, tais como Jogos Olímpicos e Copas Internacionais de Futebol, melhorias na mobilidade urbana, ações no âmbito da segurança pública, dentre outras especificações (BRASIL, 2011).

Esta modalidade também pode ser realizada através de procedimento presencial ou por meio eletrônico, e foi uma forma criada pela Administração Pública de viabilizar e agilizar as contratações para as obras e serviços de engenharia da Copa de 2014 e Olímpiadas de 2016 e de projetos específicos do governo, pois seu objetivo maior seria transformar os procedimentos licitatórios para que sejam mais eficientes e atendam ao público alvo de maneira rápida. 


\title{
EXCEÇÕESAO PROCESSO LICITATÓRIO
}

Para situações especiais previstas em lei, há situações em que não é obrigatória a realização do processo licitatório, como esclarece Justen Filho (2005, p. 227):

\begin{abstract}
A supremacia do interesse público fundamenta a exigência, com regra geral, de licitação prévia para contratações em que a licitação formal seria impossível ou frustraria a própria consecução dos interesses públicos. O procedimento licitatório normal conduziria ao sacrifício do interesse público e não asseguraria a contratação mais vantajosa. Por isso, autoriza-se a Administração a adotar um outro procedimento, em que formalidades são suprimidas ou substituídas por outras.
\end{abstract}

Porém, o fato de não realizar a licitação ainda atenderá ao princípio da legalidade, pois a Lei $\mathrm{n}^{\circ}$ 8.666/1993 institui, nos artigos 24 e 25, os casos que são dispensáveis e inexigíveis de licitação, respectivamente, distinguindo assim dois procedimentos a serem realizados: a dispensa e a inexigibilidade de licitação.

A inexigibilidade é realizada quando não há possibilidade de competição entre os fornecedores para que seja efetivada a contratação ou aquisição. A Lei 8.666/1993 em seu artigo 25 destaca possibilidades para uso de tal procedimento, como "contratação de profissional de qualquer setor artístico, para a contratação de serviços técnicos e gêneros que só possam ser fornecidos por produtor, empresa ou representante comercial exclusivo". Porém, ser um fornecedor exclusivo não deve estar ligado à marca do produto e sim a sua funcionalidade (BRASIL, 1993).

O outro caso de exceção ao processo licitatório é a dispensa de licitação que, conforme Di Pietro (2002), difere da inexigibilidade pelo fato de que nessa situação há a possibilidade de concorrência entre os fornecedores, ou seja, mais de um fornecedor tem o poder de atender ao objeto a ser adquirido pela Administração Pública. Portanto, nota-se que a dispensa de licitação é utilizada para agilizar as aquisições e/ou contratações de órgãos públicos, para atender às necessidades que precisam ser sanadas no menor tempo possível, uma vez que a realização do procedimento padrão de licitação levaria a prejuízo de maior natureza e alcance.

Porém, a lei institui condições para que a dispensa de licitação seja utilizada, listadas através de 35 incisos (até a presente data) no artigo 24 da Lei $n^{\circ} 8.666 / 1993$, que determinam as condições em que se pode fazer uso da dispensa de licitação, são casos definidos como "dispensável a licitação". Cabe salientar que são ocasiões em que a dispensa é facultativa, porém, pode tornar-se viável, por conta do menor custo para o órgão licitante e sua maior celeridade, ou seja, efetivaria a compra de maneira tempestiva, podendo ser exigível em casos de urgências, emergência, etc.

A dispensa de licitação é um procedimento muito utilizado pelos órgãos públicos, devido a sua celeridade; porém, faz-se necessário que seja realizada em ocasiões em que são realmente necessárias, seguindo todas as normas impostas. Feito isso, não haverá nenhum tipo de favorecimento a terceiros e sim à classe licitante, pois o órgão estará conseguindo sanar sua necessidade de forma rápida e, consequentemente, desempenhará de forma correta o seu papel de atendimento à coletividade, sem desrespeitar as normas de livre concorrência.

\section{DISPENSA TRADICIONAL E COTAÇÃO ELETRÔNICA}

A dispensa de licitação pode ser realizada tanto por método tradicional quanto por cotação eletrônica, que foi uma forma criada a fim de melhorar as aquisições de pequeno valor, trazendo mais transparência e uma maior competitividade entre fornecedores, além da busca de redução dos custos. $O$ método tradicional foi determinado na Lei $n^{\circ}$ 8.666/1993, e consiste na definição do objeto de aquisição/contratação e, posteriormente, numa pesquisa de mercado de no mínimo 3 (três) preços, para gerar um mapa de levantamento de preços a partir do qual se define o menor valor e se efetiva a compra.

Quanto à cotação eletrônica, foi instituída pela Portaria n 306 de 13 de dezembro de 2001, pelo Ministério do Planejamento, Orçamento e Gestão (MPOG), que determinou em seu artigo $1^{\circ}$ que: 
As aquisições de bens de pequeno valor deverão ser realizadas, no âmbito dos órgãos que compõem o Sistema Integrado de Serviços Gerais - SISG, preferencialmente, por meio do Sistema de Cotação Eletrônica de Preços, com o objetivo de ampliar a competitividade e racionalizar os procedimentos relativos a essas compras (BRASIL, 2001).

Portanto, apenas nas aquisições de bens em situações de dispensa de licitação, esta pode ser realizada por meio de cotação eletrônica. Assim, como afirma Fernandes (2005, p. 212) "a cotação eletrônica é um procedimento simplificado para a aquisição de bens de baixo valor cuja licitação é dispensada".

O Manual de Normas e Procedimentos do Ministério Público Federal afirma que a cotação eletrônica é um método que:

\begin{abstract}
Auxilia o gestor na observância dos princípios aplicáveis à gestão pública, na medida em que permite à administração selecionar a melhor proposta, ampliar a competitividade $e$ tornar mais transparentes os procedimentos relativos às compras, resguardando a isonomia e a impessoalidade da contratação. (MPF, 2017)
\end{abstract}

O início da cotação eletrônica é basicamente como ocorre a dispensa tradicional; porém, no mapa de levantamento de preços é encontrada uma média dos preços coletados, que servirá como preço de referência. A partir disso, a cotação é "lançada" em um portal eletrônico do sitio de compras governamentais, na plataforma Comprasnet, e fica disponível para acesso de fornecedores de todas as regiões que estejam cadastrados e que poderão lançar suas ofertas durante um prazo de 4 a 48 horas (definido pelo gestor do órgão licitante), funcionando praticamente como um leilão invertido, pois vence aquele que ofertar o menor valor e que posteriormente esteja com situação de regularidade em dia; caso contrario, estará desclassificado e a prioridade será do segundo colocado.

É preciso salientar que a cotação eletrônica também pode acabar não sendo satisfatória, uma vez que há situações em que os preços ofertados pelos fornecedores não são iguais ou menores que o preço de referência, tornando-se uma cotação fracassada. Pode ainda acontecer a não participação de nenhum fornecedor durante o prazo estipulado, tornando-se uma cotação deserta. Nestes casos, o ideal é que a cotação eletrônica seja realizada novamente e, se persistir o resultado, realiza-se a dispensa tradicional.

Em ambos os procedimentos de compras de pequeno valor, assim como nas licitações "maiores", são criados processos físicos que são armazenados na unidade do órgão licitante, sendo que em alguns casos sua composição já é feita inteiramente de forma eletrônica. Em sua composição deve haver um número exclusivo para cada procedimento realizado, além de documentos autorizando sua realização e a posterior contratação do fornecedor vencedor, assinados pelos representantes da administração do órgão. Para finalizar o processo, são lançadas na plataforma Comprasnet, tanto a dispensa tradicional quanto à cotação eletrônica (novamente), disponibilizando-as para as próximas fases da compra pública, o empenho e a liquidação.

\title{
METODOLOGIA
}

A metodologia deste estudo caracteriza-se por ser descritiva, com delineamento de estudo de caso e abordagem quali-quantitativa.

Para coleta de dados, utilizou-se como procedimento a análise de conteúdos extraídos do sitio de compras governamentais, acerca das cotações eletrônicas e das dispensas tradicionais. De forma complementar, em decorrência de informações incompletas nessa plataforma (ausência da data do termo de autuação e quantidade dos fornecedores participantes nas dispensas tradicionais), foram solicitadas à EMBRAPA informações necessárias para conclusão do estudo.

O primeiro passo realizado foi o levantamento no sitio de compras governamentais da numeração e 
do objeto de todos os processos de dispensa de licitação tradicional e por cotação eletrônica realizadas entre 2009 e 2016, pois foi o período em que a unidade da EMBRAPA começou a utilizar as cotações eletrônicas. Esses processos foram listados em uma planilha no Microsoft Office EXCEL, separados por ano de realização. Chegou-se a um total de 1012 (mil e doze) processos (533 cotações e 479 dispensas tradicionais).

Após o levantamento dos processos, foi necessária a realização de uma amostragem estatística para selecionar os processos que seriam analisados, o que foi feito com o sistema Statdisk. O sistema possui um nível de confiabilidade de $95 \%$ e uma margem de erro de $5 \%$. Assim, foi determinada a quantidade de 279 (duzentos e setenta e nove) processos a serem analisados, incluindo nesse montante os dois procedimentos em estudo.

Como essa quantidade amostral refere-se aos anos de 2009 a 2016, foi necessário distribui-la entre os anos, realizado por meio da representatividade, conforme pode ser observado no Quadro 01.

Quadro 01. Cálculo de representatividade por ano analisado.

\begin{tabular}{|l|c|c|c|c|c|c|c|c|c|}
\hline & $\mathbf{2 0 0 9}$ & $\mathbf{2 0 1 0}$ & $\mathbf{2 0 1 1}$ & $\mathbf{2 0 1 2}$ & $\mathbf{2 0 1 3}$ & $\mathbf{2 0 1 4}$ & $\mathbf{2 0 1 5}$ & $\mathbf{2 0 1 6}$ & Total \\
\hline Dispensa Tradicional & 38 & 52 & 83 & 81 & 83 & 54 & 46 & 42 & 479 \\
\hline Cotação Eletrônica & 89 & 105 & 48 & 62 & 69 & 58 & 61 & 41 & 533 \\
\hline Total Geral & 127 & 157 & 131 & 143 & 152 & 112 & 107 & 83 & 1012 \\
\hline Porcentagem (\%) & 12,55 & 15,51 & 12,95 & 14,13 & 15,02 & 11,07 & 10,57 & 8,2 & 100 \\
\hline $\begin{array}{l}\text { Quantidade de } \\
\text { Processos para análise }\end{array}$ & 35 & 43 & 36 & 39 & 42 & 31 & 29 & 24 & 279 \\
\hline
\end{tabular}

Fonte: Elaborado pelo autor (2018)

Depois de encontrado o total de processos para análise por ano, foi necessário identificar aqueles que seriam analisados. Para tanto, o montante dos processos foi listado em uma planilha EXCEL por ano de realização.

Porém, a numeração dos mesmos não seguia uma ordem cronológica exata $(1,2,3,4 \ldots)$ devido a algumas particularidades, como o período de realização dos processos e porque foram desconsideradas as dispensas tradicionais de serviço, pois as cotações eletrônicas são realizadas apenas para aquisições, tornando a comparação mais justa e igualitária. Para solucionar esses impasses, foi adicionada uma coluna na planilha com numeração em ordem cronológica, facilitando a separação dos processos.

Após organização e separação dos processos, o próximo passo foi realizar a amostragem, do tipo aleatória sem reposição, com auxílio do programa BioEstat 5.3, sendo preciso informar o total da população (total de processos de dispensa tradicional e cotação eletrônica para análise) e o tamanho da amostra (encontrado através do cálculo de representatividade apresentado no Quadro 01), para que o programa disponibilize uma sequência de números. Tal procedimento foi realizado para cada ano, sendo que o número disponibilizado representou o número da linha e o ano representou a coluna da planilha.

A coleta dos dados foi realizada no sitio de compras governamentais, onde são disponibilizadas informações mais especificas dos processos licitatórios realizados. É necessário apenas preencher informações autoexplicativas para a identificação do órgão público e da modalidade de licitação desejada.

Esse procedimento foi realizado para todos os 279 processos anteriormente selecionados para análise, porém algumas informações necessárias, como a data em que foi iniciado cada processo, não são disponibilizadas e, então, fez-se necessário que esses dados fossem solicitados à EMBRAPA. Porém, houve trinta e seis processos em situação pendente de adjudicação e trinta cancelados, que não puderam ser comparados quanto à tempestividade e competitividade. Consequentemente, eles foram excluídos, restando 213 (duzentos e treze) processos para análise.

Além dos processos que foram excluídos da pesquisa, ainda houve situações de processos que 
não foram encontrados fisicamente, portanto também foram excluídos da comparação quanto às variáveis de tempestividade e economicidade, mas continuaram a ser considerados para a variável de economicidade, por ter sido possível a coleta dos dados necessários. Depois de finalizada a coleta dos dados necessários para as comparações entre as dispensas tradicionais e as cotações eletrônicas, procedeu-se a análise dos dados.

A tempestividade foi analisada levando-se em conta a quantidade de dias necessários para a finalização de cada processo de dispensa, seja por cotação eletrônica ou por dispensa tradicional. A data do "Termo de Autuação" foi considerada como a data inicial em ambos os processos, e a final foi determinada pela data de adjudicação/homologação no caso das cotações e do "Ato de Autorização" nos casos de dispensa tradicional.

Quanto à economicidade, ela foi analisada através do somatório dos valores de aquisição dos processos dividido pela quantidade de processos analisados. O procedimento foi realizado por processo e por ano de realização. Também foi analisado o percentual de ganho nas cotações eletrônicas, através da diferença entre os valores de referência e de aquisição.

Em relação à competitividade, a mesma foi analisada através da soma da quantidade de fornecedores dos processos analisados e a divisão pela quantidade dos processos por ano, verificando assim qual método tem possibilidade de maior competitividade entre os fornecedores, ou seja, se a cotação eletrônica ou a dispensa tradicional possui números mais elevados de fornecedores participantes.

Após a análise dos dados da pesquisa, os resultados da comparação entre os processos foram apresentados por meio de tabelas e gráficos, para poder concluir qual dos procedimentos tem sido mais vantajoso para a unidade da EMBRAPA, no que diz respeito à tempestividade, economicidade e competitividade.

\section{RESULTADOS E DISCUSSÃO}

Neste tópico são apresentados os resultados encontrados após análise dos dados, coletados através do levantamento de informações do sítio de compras governamentais e dados colhidos nos processos físicos na unidade da EMBRAPA.

\section{PROCESSOS ANALISADOS QUANTO À TEMPESTIVIDADE E COMPETITIVIDADE}

$\mathrm{Na}$ análise dos processos, quanto às variáveis de tempestividade e competitividade, foram necessárias informações de número e objeto para identificação dos processos, além da data do termo de autuação, representando o início e data do ato de autorização da dispensa tradicional e da adjudicação/homologação das cotações como o término, definindo assim um ciclo de dias.

Para determinar a competitividade dos processos, foi realizada a divisão do somatório dos fornecedores participantes pelo somatório dos processos analisados, determinando uma média de fornecedores participantes. No Quadro 02 são apresentados os dados e o resultado do cálculo da tempestividade.

O Gráfico 01 mostra a comparação dos resultados obtidos, necessária para identificar o mecanismo mais vantajoso para EMBRAPA quanto ao tempo de realização dos mesmos.

Ao analisar o Gráfico 01, observa-se que do ano de 2009 ao ano de 2012, as cotações eletrônicas levavam mais dias para serem realizadas que a dispensa tradicional. Essa situação pode ter ocorrido devido ao pouco tempo de sua implementação na EMBRAPA, que ocorreu no ano de 2009, quando os gestores responsáveis ainda não teriam experiência na realização dos processos.

Já a partir do ano de 2013 até o ano de 2016, a situação se inverteu, sendo a cotação mais célere que a dispensa tradicional, chegando ao ponto de que no último ano em estudo (2016), a média de realização dos processos de cotações era de apenas 5 (cinco) dias, mostrando que os gestores se habituaram aos procedimentos de realização do processo. Portanto, notou-se que a cotação eletrônica foi se aprimorando, diminuindo o tempo de realização e assim atendendo ao expresso na Portaria $\mathrm{n}^{\circ}$ 
306/2001 de "racionalizar procedimentos, propiciando maior agilidade aos referidos processos de aquisição.” (BRASIL, 2001).

Em relação à competitividade, foram apresentadas, no Quadro 03, as quantidades de fornecedores e de processos, bem como a média de fornecedores participantes.

Finalizado o cálculo da competitividade dos processos, foi necessária a comparação entre os resultados encontrados para o método tradicional e por cotação eletrônica afim de identificar em qual deles houve maior competitividade (Gráfico 02).

Quadro 02. Cálculo da média de tempo de realização dos processos.

\begin{tabular}{|c|l|c|c|c|}
\hline & \multicolumn{1}{|c|}{ MÉTODO } & $\begin{array}{c}\text { SOMA DO } \\
\text { CICLO DE DIAS }\end{array}$ & $\begin{array}{c}\text { QUANTIDADE DE } \\
\text { PROCESSOS }\end{array}$ & $\begin{array}{c}\text { MÉDIA DE TEMPO } \\
\text { DA REALIZAÇÃO }\end{array}$ \\
\hline \multirow{2}{*}{2009} & 206 & 09 & $206 / 9=23$ \\
\hline \multirow{2}{*}{2010} & Tradicional & 800 & 15 & $800 / 15=53$ \\
\cline { 2 - 5 } & Tração eletrônica & 572 & 13 & $572 / 13=44$ \\
\cline { 2 - 5 } & Cotação eletrônica & 985 & 15 & $985 / 15=66$ \\
\hline \multirow{2}{*}{2011} & Tradicional & 518 & 22 & $518 / 22=24$ \\
\cline { 2 - 5 } & Cotação eletrônica & 322 & 08 & $322 / 8=40$ \\
\hline \multirow{2}{*}{2012} & Tradicional & 321 & 18 & $321 / 18=18$ \\
\cline { 2 - 5 } & Cotação eletrônica & 284 & 08 & $284 / 8=36$ \\
\hline \multirow{2}{*}{2013} & Tradicional & 531 & 14 & $531 / 14=38$ \\
\cline { 2 - 5 } & Cotação eletrônica & 284 & 12 & $284 / 12=24$ \\
\hline \multirow{2}{*}{2014} & Tradicional & 510 & 13 & $19 / 13=39$ \\
\cline { 2 - 5 } & Cotação eletrônica & 195 & 08 & $417 / 12=35$ \\
\hline \multirow{2}{*}{2015} & Tradicional & 417 & 12 & $250 / 13=19$ \\
\cline { 2 - 5 } & Cotação eletrônica & 250 & 13 & $154 / 13=12$ \\
\hline \multirow{2}{*}{2016} & Tradicional & 154 & 13 & $41 / 8=05$ \\
\cline { 2 - 5 } & Cotação eletrônica & 41 & 08 & 0 \\
\hline
\end{tabular}

Fonte: Dados da Pesquisa (2018)

Gráfico 01. Comparação dos métodos quanto à tempestividade.

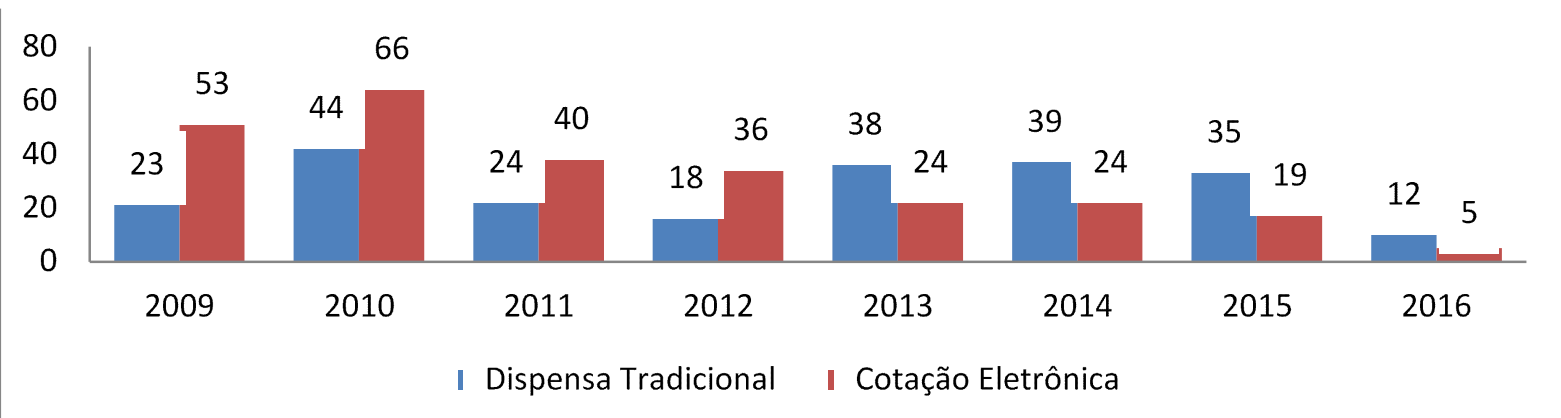

Fonte: Dados da Pesquisa (2018)

Gráfico 02. Comparação dos métodos quanto à competividade.

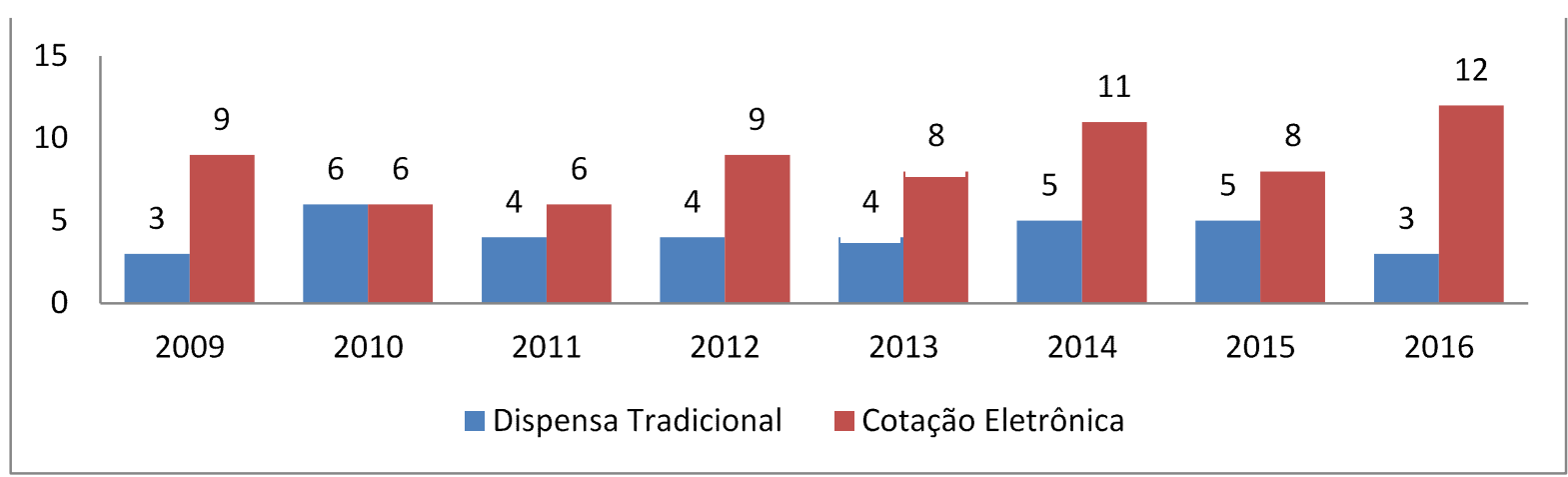

Fonte: Dados da Pesquisa (2018) 
Observando o Gráfico 02, notou-se que, em relação à competitividade, a cotação obteve um número maior de média de fornecedores na grande maioria dos anos em estudo, demonstrando ser mais competitiva que o método tradicional.

\section{PROCESSOS ANALISADOS QUANTO À ECONOMICIDADE}

$\mathrm{Na}$ análise dos processos quanto à economicidade foi encontrada a média de valor das aquisições através da divisão do somatório destes valores pelo total de processos (Quadro 04).

Quadro 03. Cálculo da média de fornecedores participantes dos processos.

\begin{tabular}{|c|c|c|c|c|}
\hline & MÉTODO & $\begin{array}{l}\text { QTD. DE } \\
\text { FORNEC. }\end{array}$ & $\begin{array}{l}\text { QTD. DE } \\
\text { PROCES. }\end{array}$ & $\begin{array}{l}\text { MÉDIA DE FORNEC. } \\
\text { PARTICIPANTES }\end{array}$ \\
\hline \multirow{2}{*}{2009} & Tradicional & 30 & 09 & $30 / 9=03$ \\
\hline & Cotação eletrônica & 142 & 15 & $142 / 15=09$ \\
\hline \multirow{2}{*}{2010} & Tradicional & 72 & 13 & $72 / 13=06$ \\
\hline & Cotação eletrônica & 95 & 15 & $95 / 15=06$ \\
\hline \multirow{2}{*}{2011} & Tradicional & 89 & 22 & $89 / 22=04$ \\
\hline & Cotação eletrônica & 44 & 08 & $44 / 8=06$ \\
\hline \multirow{2}{*}{2012} & Tradicional & 78 & 18 & $78 / 18=04$ \\
\hline & Cotação eletrônica & 74 & 08 & $74 / 8=09$ \\
\hline \multirow{2}{*}{2013} & Tradicional & 61 & 14 & $61 / 14=04$ \\
\hline & Cotação eletrônica & 92 & 12 & $92 / 12=08$ \\
\hline \multirow{2}{*}{2014} & Tradicional & 67 & 13 & $67 / 13=05$ \\
\hline & Cotação eletrônica & 88 & 08 & $88 / 8=11$ \\
\hline \multirow{2}{*}{2015} & Tradicional & 59 & 12 & $59 / 12=05$ \\
\hline & Cotação eletrônica & 98 & 13 & $98 / 13=08$ \\
\hline \multirow{2}{*}{2016} & Tradicional & 38 & 13 & $38 / 13=03$ \\
\hline & Cotação eletrônica & 93 & 08 & $93 / 8=12$ \\
\hline
\end{tabular}

Fonte: Dados da Pesquisa (2018)

Quadro 04. Cálculo da média dos valores de aquisição.

\begin{tabular}{|l|l|c|c|c|}
\hline \multirow{2}{*}{ MÉTODO } & $\begin{array}{c}\text { VALORES DE } \\
\text { AQUISIÇÃO }\end{array}$ & $\begin{array}{c}\text { QTD. DE } \\
\text { PROCES. }\end{array}$ & $\begin{array}{c}\text { VALORES DE } \\
\text { AQUIS. / QTD. DE } \\
\text { PROCES. }\end{array}$ \\
\hline \multirow{2}{*}{2009} & Tradicional & $8.666,74$ & 09 & $1.175,97$ \\
\cline { 2 - 5 } & Cotação eletrônica & $22.396,84$ & 15 & $1.493,12$ \\
\hline \multirow{2}{*}{2010} & Tradicional & $29.994,68$ & 13 & $2.307,28$ \\
\cline { 2 - 5 } & Cotação eletrônica & $24.828,34$ & 15 & $1.655,22$ \\
\hline \multirow{2}{*}{2011} & Tradicional & $61.502,62$ & 25 & $2.460,10$ \\
\cline { 2 - 5 } & Cotação eletrônica & $7.679,78$ & 08 & 959,97 \\
\hline \multirow{2}{*}{2012} & Tradicional & $56.061,03$ & 20 & $2.803,05$ \\
\cline { 2 - 5 } & Cotação eletrônica & $7.362,49$ & 08 & 920,31 \\
\hline \multirow{2}{*}{2013} & Tradicional & $41.809,16$ & 17 & $2.459,36$ \\
\cline { 2 - 5 } & Cotação eletrônica & $36.929,28$ & 13 & $2.840,71$ \\
\hline \multirow{2}{*}{2014} & Tradicional & $22.246,81$ & 14 & $1.589,06$ \\
\cline { 2 - 5 } & Cotação eletrônica & $29.017,29$ & 10 & $2.901,73$ \\
\hline \multirow{2}{*}{2015} & Tradicional & $36.264,17$ & 12 & $3.022,01$ \\
\cline { 2 - 5 } & Cotação eletrônica & $38.380,65$ & 13 & $2.952,36$ \\
\hline \multirow{2}{*}{2016} & Tradicional & $46.259,76$ & 13 & $3.558,44$ \\
\cline { 2 - 5 } & Cotação eletrônica & $21.457,67$ & 08 & $2.682,21$ \\
\hline
\end{tabular}

Fonte: Dados da Pesquisa (2018) 
Após realizado o cálculo da economicidade (Quadro 04), o próximo passo foi a apresentação e comparação dos resultados nos métodos por cotação eletrônica e por dispensa tradicional, os quais podem ser visualizados no Gráfico 03.

Gráfico 03. Comparação dos métodos quanto a economicidade.

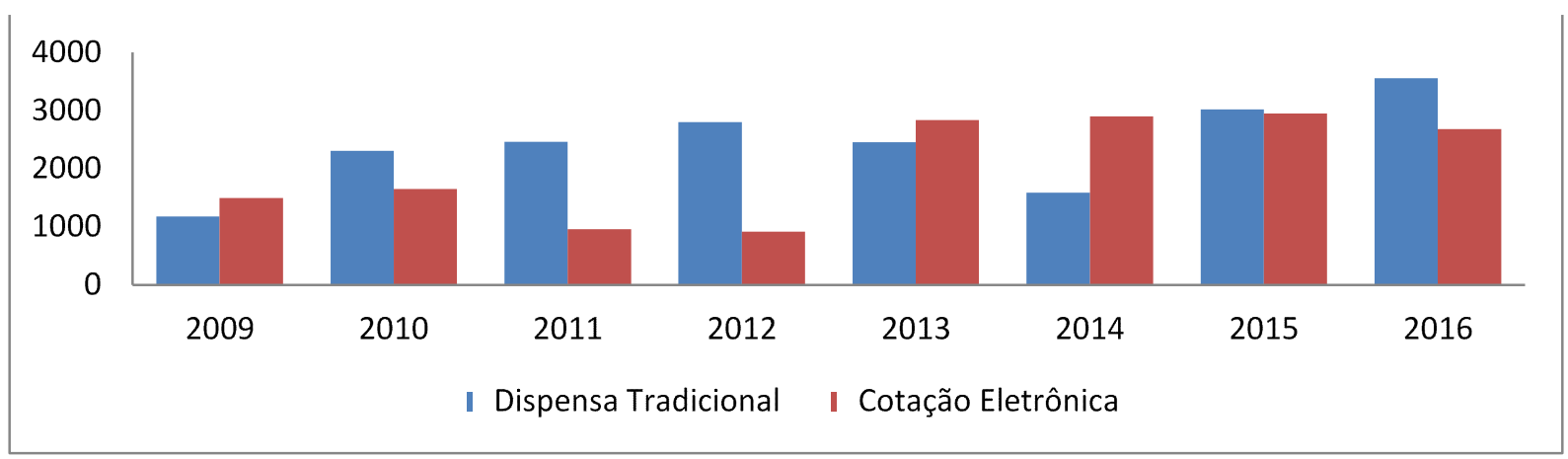

Fonte: Dados da Pesquisa (2018)

Como pode ser observado no Gráfico 03 , no ano de 2009, a média dos valores de aquisição por cotação eletrônica foi maior que por dispensa tradicional; já nos três anos seguintes essa situação se inverteu, chegando a diferença de valores consideráveis nos anos de 2011 e 2012. As cotações obtiveram médias maiores nos anos de 2013 e 2014; já em 2015 e 2016 as dispensas tradicionais alcançaram os maiores valores; portanto, as cotações eletrônicas demonstraram-se mais vantajosas para a EMBRAPA.

De forma complementar, ainda foi calculado o nível de percentual de ganho nas cotações eletrônicas (Gráfico 04), que é a diferença entre o valor de referência e o valor de aquisição, visto que no caso de realização da dispensa tradicional o valor de referência seria a média de preço que efetivaria a aquisição do objeto.

Gráfico 04. Comparação dos valores de referencia e valores de aquisição das cotações eletrônicas.

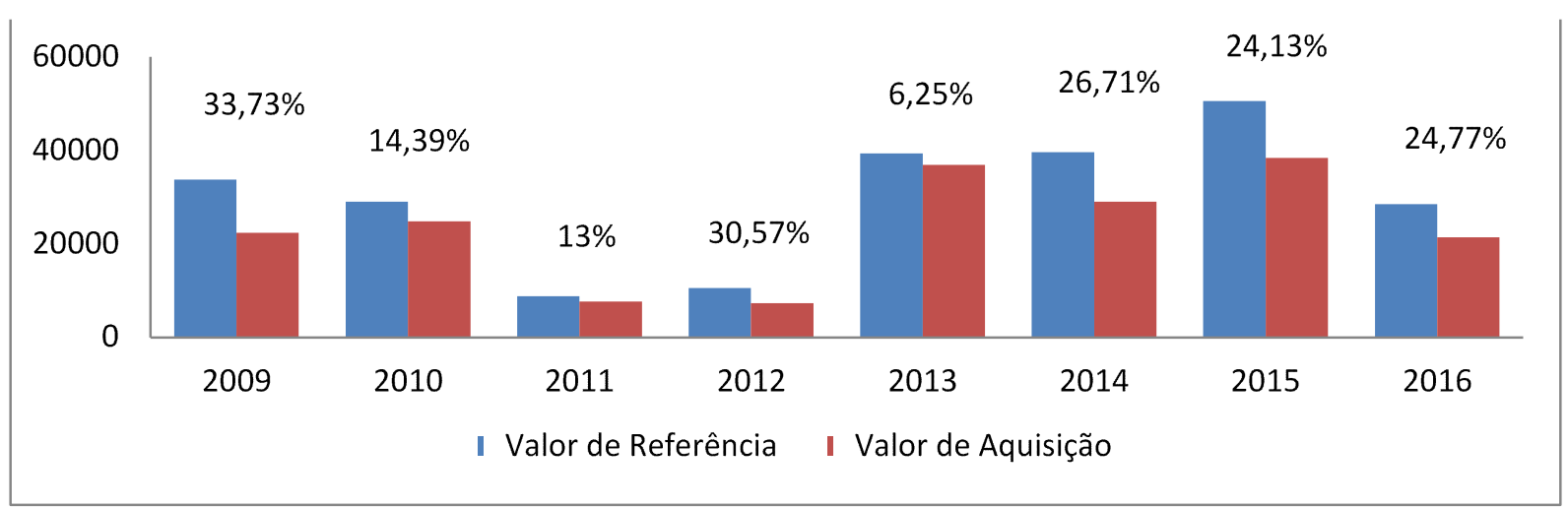

Fonte: Dados da Pesquisa (2018).

Analisando o Gráfico 04, observa-se a comparação dos valores especificados e os percentuais que representam os ganhos de valor de cada ano em estudo, destacando-se que em apenas um dos anos o percentual foi menor que $10 \%$, enquanto que nos demais se manteve entre 13 e $34 \%$.

Fazendo uma comparação com os resultados do Gráfico 02 , por exemplo, nota-se que há uma relação com os percentuais de ganho do Gráfico 04, pois nos anos em que a diferença na quantidade de fornecedores entre os métodos foi maior, como os anos de 2009, 2012, 2014 e 2016, quando as diferenças se mantiveram entre 6, 5, 6 e 9 de fornecedores participantes, respectivamente, foram também os anos em que os percentuais foram mais elevados. 
Com estes dados comprova-se que quanto maior a competitividade entre os fornecedores, maior a tendência de diminuição dos valores de aquisição e, consequentemente, maior o aumento dos ganhos, indicando que a cotação eletrônica tende a ser mais econômica para a EMBRAPA.

\section{CONSIDERAÇÕES FINAIS}

O presente estudo buscou responder como a aquisição de bens que se enquadram nas situações de dispensa de licitação são realizadas em relação comparativa com a tempestividade, economicidade e competitividade.

Observou-se que em uma comparação entre os dois métodos citados, a cotação eletrônica mostrou-se mais tempestiva, em desenvolvimento, pois obteve resultados desfavoráveis nos primeiros anos em estudo, porém nos últimos anos os resultados foram favoráveis, chegando a marca de apenas cinco dias no ano de 2016, notando que a prática foi aperfeiçoada com o passar dos anos.

Quanto à competitividade, a cotação eletrônica também demonstrou ser mais vantajosa que a dispensa tradicional, pois em sete dos oito anos em estudo, a média de fornecedores participantes foi maior, o que na teoria implica em maiores negociações e consequentemente diminuição de valores.

E em relação à economicidade, comprovou-se que a média das compras realizadas por meio de cotação eletrônica foram menores em cinco dos anos em estudo. De forma complementar, ainda foram apresentados os percentuais de ganho das cotações, embasando os resultados e comprovando que a cotação eletrônica realmente é mais econômica que a dispensa tradicional.

Propõe-se que os gestores responsáveis pela realização dos processos licitatórios utilizem mais as cotações eletrônicas, devido às vantagens comprovadas no presente estudo, deixando o método tradicional apenas para situações especificas. Seja qual for o método escolhido, também propõe-se que sejam coletados mais do que três preços de mercado (número mínimo determinado), e que esses também sejam negociados com os fornecedores afim de que aumente a competitividade e consequentemente diminuam os valores.

E academicamente, propõe-se que sejam realizadas mais pesquisas semelhantes, em outras entidades públicas ou até mesmo uma comparação entre duas ou mais unidades da própria EMBRAPA, a fim de identificar e analisar as diferenças encontradas.

\section{REFERENCIAS}

BRASIL. Lei n 8.666, de 21 de junho de 1993. Lei de Licitações e Contratos Administrativos. Disponível em: <http://www.planalto.gov.br/ccivil_03/leis/L8666cons.htm>. Acesso em: 22 de setembro de 2017.

. Lei $n^{\circ} 10.520$, de 17 de julho de 2002. Lei que institui a modalidade delicitação denominada

Pregão. Disponível em: <http://www.planalto.gov.br/ccivil_03/leis/2002//10520.htm> Acesso em: 14 de outubro de 2017.

. Lei $n^{\circ} 12.462$, de 04 de Agosto de 2011. Lei que Institui o Regime Diferenciado de Contratações

Públicas - RDC. Disponível em: <http://www.planalto.gov.br/ccivil_03/_ato2011-

2014/2011/lei/l12462.htm>Acesso em 21 de Outubro de 2017.

Ministério Público Federal - MPF. Manual de Normas e Procedimentos: Dispensa de licitação por Cotação Eletrônica de Preços. Brasília, 2017. 54 p. Disponível em: < http://www.mpf.mp.br/conheca-o-mpf/gestaoestrategica-e-modernizacao-do-mpf/escritorio-de-processos/manuais-de-normas-e-procedimentos/manual-cotacaoeletronica-is_sa_2017_1.pdf>. Acesso em: 29 de Outubro de 2017

Portaria $n^{\circ}$ 306/2001, de 13 de Dezembro de 2001. Portaria de implantação do Sistema de Cotação Eletrônica de Preços. Disponível em: <http://www.comprasnet.gov.br/legislacao/portarias/p306 01.htm>. Acesso em: 28 de Outubro de 2017. 
COSTIN, Claudia. Administração Pública. Rio de Janeiro - Rj: Elsevier, 2010.

DALLARI, Adilson Abreu. Contrato regido por cláusulas uniformes. Revista do Tribunal de Contas do Estado de São Paulo, São Paulo, p. 29-32, maio, 1993.

DI PIETRO, Maria Sylvia Zanella. Direito administrativo. 14 ed. São Paulo: Atlas, 2002.

FERNANDES, Ciro Campos Christo. Abrangência, inserção e impacto transformador dos sistemas de compras eletrônicas na administração pública - análise do Siasg/Comprasnet. Revista do Serviço Público, Brasília DF, v. 56, n. 2, p. 195-216, abr./jun. 2005. Disponível em:

<http://repositorio.enap.gov.br/bitstream/1/1543/1/2005\%20Vol.56\%2cn.2\%20Fernandes.pdf>. Acesso em: 15 de Outubro de 2017.

JUSTEN FILHO. Marçal, Comentários ä Lei de Licitações e Contratos Administrativos 11 ed. Dialética: São Paulo, 2005.

KOHAMA, Heilio. Contabilidade Pública: Teoria e Prática. 11. ed. São Paulo: Atlas, 2010.

SILVA, Erivam Paulo da. O uso do Poder de Compra do Estado como Instrumento de Política Pública: A Lei no 123/2006, sua implementação. Dissertação de Mestrado. FGV - Rio de Janeiro, 2008. Disponível em: < http://bibliotecadigital.fgv.br/dspace/bitstream/handle/10438/3408/erivam.pdf?sequence=1\&isAllowed=y $>$. Acesso em: 08 de Outubro de 2017.

SILVA, Valmir Leôncio da. A Nova Contabilidade aplicada ao Setor Público: Uma abordagem prática. 3. ed. São Paulo: Atlas S.a, 2014.

VASCONCELOS, Cristina Demartini Gontijo. Processo eletrônico de compras: celeridade e transparência. Brasília: 2013. 